\title{
THOMPSON PROSTHESIS FOR FRACTURED NECK OF FEMUR
}

\section{A COMPARISON OF SURGICAL APPROACHES}

\author{
R. N.-W. Chan, Bath, and J. Hoskinson, Oxford, England
}

From the Bath and Wessex Orthopaedic Hospital, Bath

\begin{abstract}
The records of $\mathbf{2 4 3}$ patients with Thompson prostheses for displaced femoral neck fractures have been studied.

One hundred and seven prostheses were inserted through an anterior approach and 136 by a posterior approach. The short-term results and complications in these otherwise comparable groups are discussed. The infection rate of 18.5 per cent in the group operated upon by the posterior approach was thrice that after operations by the anterior route (6.5 per cent infected). Drained wounds had significantly less infection (6.3 per cent) compared with the undrained group (28 per cent infected). Other factors influencing the infection rate are discussed. The anterior approach offered greater stability. Of the twenty dislocations in the series, nineteen followed operations by the posterior approach.

The mortality rate six weeks after operation was 6.5 per cent after the anterior approach and 20.6 per cent after the posterior approach. Statistical analysis significantly favours the anterior approach.
\end{abstract}

The management of displaced subcapital femoral fractures continues to divide opinion among orthopaedic surgeons. The role of the femoral head prosthesis has been the subject of many conflicting reports and divergent views over the past ten years. Several papers have recorded excellent results in both the short and the long term (Hinchey and Day 1964; Burwell 1967; Polyzoides 1971; Riska 1971), but others have condemned its routine use (Nicoll 1963; Boyd and Salvatore 1964; Hunter 1969, 1974; Lunt 1971).

The diversity of opinion and results can be explained in part by the fact that different reports must, of necessity, involve different clinical factors and criteria, thus making comparison difficult. Careful review of the literature suggests that some of these discrepancies may depend on a different surgical approach to the hip.

It is the purpose of this paper to discuss the shortterm morbidity and mortality after prosthetic replacement of the femoral head and to compare the results after anterior and posterior surgical approaches to the hip.

\section{MATERIAL AND METHOD}

In the Bath Clinical Area between June 1968 and May 1974, 330 patients with displaced subcapital fractures of the femur were treated by prosthetic replacement. In this series only patients with Thompson prostheses were considered; fifty patients with Austin Moore prostheses have been excluded. In addition, thirty-seven cases were rejected because of inadequate information.

Of the 243 hips left for review, 227 had primary prosthetic replacement for fresh subcapital fractures: the remaining sixteen operations were secondary to unsuccessful nailing operations. One hundred and seven pros- theses were inserted through the anterior approach and 136 by the posterior route. All case notes were studied and from these the relevant information was obtained and tabulated. Analysis covered a period of six weeks from the time of operation unless death occurred during this period.

\section{SURGICAL APPROACH}

The surgical approach to the hip was either by the anterior or by the posterior route, depending upon the preference of the surgeon performing the operation. The anterior approach is basically that described by SmithPetersen with minor modifications (Henry 1957). The hip capsule is divided anteriorly and the prosthesis is most stable with the hip in flexion and medial rotation. The posterior (southern) approach is that described by Moore (1959). The lateral rotators are divided and the hip is most stable in a position of extension and lateral rotation.

The nursing care and post-operative management of all patients were undertaken in the same orthopaedic unit, and no surgeon had a policy relating to antibiotics, skin preparation, skin traction or prophylactic anticoagulants that would give bias to either group.

The two groups are therefore strictly comparable in all respects other than the surgical approach. Table I indicates some of the randomly selected criteria for comparability. Analysis of the age distribution of the two groups shows a similar distribution.

Patients with a pre-existing disability such as hemiplegia, heart failure, diabetes or mental disorder make up the group labelled as "significant pre-operative state" in Table I. The "admissions other than from home" 
include patients from long-stay geriatric units, nursing homes and mental institutions. Trainee surgeons, defined as registrars and senior house officers, were responsible for an almost equal number of operations in each group. parisons are valid since the same method was used for both groups.

The anterior approach is commonly thought to be associated with higher blood loss (Anderson, Hamsa and

TABLE I

Criteria for Comparabiuty of the Two Methods of Surgical APPROACH

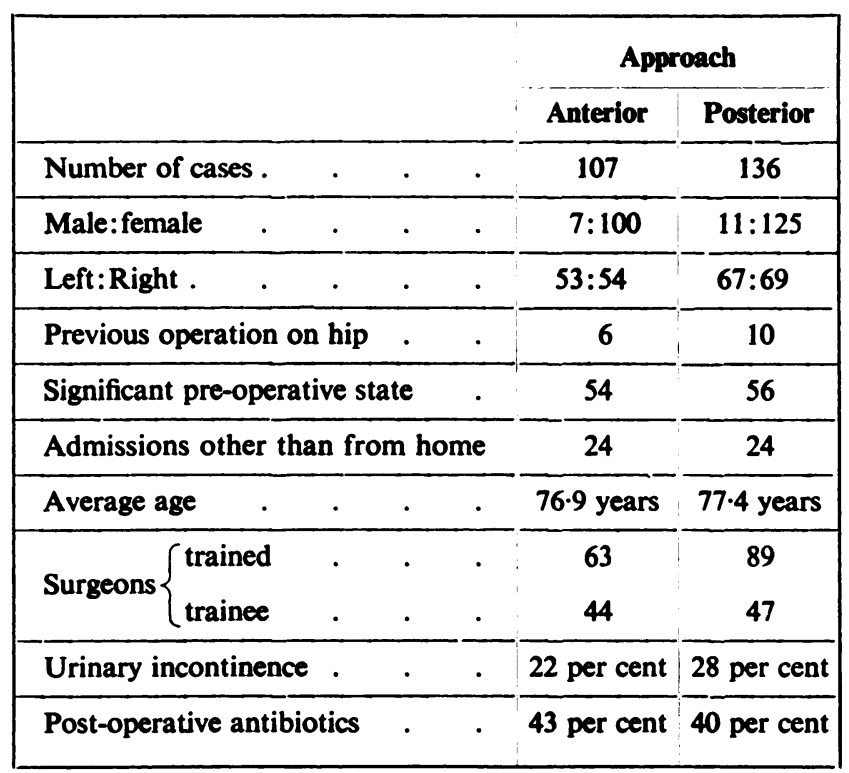

TABLE II

Comparison of Blood Loss

\begin{tabular}{|c|c|c|c|c|c|c|c|}
\hline \multirow[b]{2}{*}{ Approach } & \multicolumn{3}{|c|}{$\begin{array}{l}\text { Operative blood loss } \\
\text { (millilitres) }\end{array}$} & \multicolumn{3}{|c|}{$\begin{array}{c}\text { Post-operative drainage } \\
\text { (millititres) }\end{array}$} & \multirow{2}{*}{$\begin{array}{l}\text { Totals } \\
\text { (milli- } \\
\text { litres) }\end{array}$} \\
\hline & $\begin{array}{l}\text { Cases } \\
\text { studied }\end{array}$ & Average & Range & $\begin{array}{l}\text { Cases } \\
\text { studied }\end{array}$ & Average & Range & \\
\hline Anterior & 43 & 230 & $100-500$ & 31 & 210 & $60-550$ & 440 \\
\hline Posterior & 45 & 320 & $50-1,200$ & 35 & 280 & $70-650$ & 600 \\
\hline
\end{tabular}

TABLE III

INFECTION RATE

\begin{tabular}{|c|c|c|c|c|}
\hline \multirow[b]{2}{*}{ Approach } & \multicolumn{2}{|c|}{ All infections } & \multicolumn{2}{|c|}{ Deep infections } \\
\hline & Number & Per cent & Number & Per cent \\
\hline Anterior & 7 & $6 \cdot 5$ & 3 & $2 \cdot 8$ \\
\hline Posterior . & 25 & $18 \cdot 5$ & 2 & 1.5 \\
\hline Total overall rate & 32 & $13 \cdot 2$ & 5 & $2 \cdot 1$ \\
\hline
\end{tabular}

\section{RESULTS}

Blood loss-To the best of our knowledge, comparison of the loss of blood in anterior and posterior approaches has not been reported previously. Loss during operation was assessed by weighing the swabs and loss after operation by measurement of drainage into a suction bottle. Though this tends to underestimate blood loss, com-
TABLE IV

BACTERIOLOGY OF INFECTIONS

\begin{tabular}{|c|c|c|c|}
\hline Approach & $\begin{array}{c}\text { Staphylococcus } \\
\text { aureus }\end{array}$ & $\begin{array}{c}\text { Mixed growths: } \\
\text { staphylococcus, } \\
\text { streptococeus, } \\
\text { diptheroids, } \\
\text { skin commensals }\end{array}$ & $\begin{array}{c}\text { Coliforms } \\
\text { E. coll } \\
\text { proteus } \\
\text { pseudomonas }\end{array}$ \\
\hline Anterior & 7 & - & - \\
\hline Posterior & 10 & 6 & 9 \\
\hline
\end{tabular}

Waring 1964), but in this series it compares favourably with the posterior route. The average total loss (Table II) by the anterior route was $\mathbf{4 4 0}$ millilitres compared with 600 millilitres by the posterior.

Infection--Infected cases are those producing pathogenic organisms on culture of wound swabs and include swabs taken in the presence of haematoma or serous discharge. This gives a higher infection rate than is significant 
clinically. The overall infection rate was $13 \cdot 2$ per cent. Five patients ( $2 \cdot 1$ per cent) developed deep infection; the remainder were superficial (Table III). Although these figures are within the ranges quoted in previous publications, they are nevertheless high for prosthetic surgery. The infection rate was almost three times higher in the posterior group than the anterior group $(p<0.02)$.

TABLE V

URINARY INCONTINENCE AND WOUND INFECTION

\begin{tabular}{|l|c|c|}
\hline & Anterior approach & Posterior approach \\
\hline Urinary incontinence & 24 (22 per cent) & 38 (28 per cent) \\
\hline Wound infection $\cdot$ & 3 & $14^{*}$ \\
\hline
\end{tabular}

* Eight patients in this group had identical organisms in both wound and urine.

TABLE VI

Wound Drainage and Infection Rates

\begin{tabular}{|l|c|c|c|}
\hline & Number & Infections & $\begin{array}{c}\text { Infection rate } \\
\text { (per cent) }\end{array}$ \\
\hline Suction drainage . & 158 & 10 & 6.3 \\
\hline No drainage & 85 & 24 & 28 \\
\hline
\end{tabular}

TABLE VII

Factors Affecting Infection Rate Average infection rate $=13$ per cent

\begin{tabular}{|l|c|c|}
\hline & $\begin{array}{c}\text { Number of } \\
\text { infections }\end{array}$ & $\begin{array}{c}\text { Infection rate } \\
\text { (per cent })\end{array}$ \\
\hline Dislocation of prosthesis & $9 / 20$ & 45 \\
\hline Previous operation on hip . & $6 / 16$ & 37.5 \\
\hline No suction drainage & $24 / 85$ & 28 \\
\hline Urinary incontinence $\cdot$. & $17 / 62$ & 27 \\
\hline Trainee surgeons . & $14 / 91$ & 16 \\
\hline Surgical approach $\left\{\begin{array}{l}\text { anterior } \\
\text { posterior . }\end{array}\right.$ & $25 / 107$ & 6.5 \\
\hline
\end{tabular}

TABLE VIII

Dislocation Rate

\begin{tabular}{|c|c|c|c|c|}
\hline Anterior approach & . & . & $1 / 107$ & 0.9 per cent \\
\hline Posterior approach & . & . & $19 / 136$ & 14 per cent \\
\hline Total overall rate & . & . & $20 / 243$ & $8 \cdot 2$ per cent \\
\hline
\end{tabular}

Bacteriological analysis (Table IV) shows that staphylococcus aureus was responsible for all the infections in the anterior group and a similar number in the posterior group. The posterior incision is sited in an area of urinary and faecal soiling, and authors have previously expressed concern regarding this approach (Badgely 1961; King 1964). The association between urinary incontinence and wound infection is compared with respect to the surgical approach in Table $\mathrm{V}$, showing that one in eight patients in the anterior group became infected, compared with more than one in three patients in the posterior group $(p<0 \cdot 1)$. Moreover, of the fourteen infected cases in the latter group, eight patients had identical organisms in both wound and urine cultures. In this series, therefore, the posterior approach carried a much higher risk of infection and this risk was greatly increased in the presence of urinary incontinence.

The majority of patients (65 per cent) had suction drainage of the wounds. Table VI indicates the influence of this in reducing the rate of infection. Other factors influencing the infection rate are shown in Table VII. Patients who had had previous hip operations (failed pinning) had an infection rate of 37.5 per cent-almost three times the average rate-and this is clearly a high risk group. Surgical experience did not appear to be a very important factor and the infection rate of 16 per cent by trainee surgeons was only marginally higher than the 13 per cent infection rate in the hands of their trained colleagues.

We cannot comment on the value of antibiotics because, in general, pre-operative antibiotics were not given, nor were serum levels monitored. Antibiotics were used in 40 per cent of cases and these were equally divided between the two groups.

Dislocation-There were twenty dislocations among 243 replacements, an incidence of 8.2 per cent. This group had a slightly higher average age (seventy-nine years). The general medical profile was also less favourable: five patients were from mental institutions and a further thirteen had significant pre-operative medical illnesses including cerebro-vascular insufficiency and cardiac failure. Twelve operations were performed by trained staff; eight by trainee surgeons. The mortality rate in this group was 60 per cent. Post-mortem studies related the cause of death to pulmonary embolism in four patients, bronchopneumonia in three patients and cerebro-vascular incidents in two. Three patients did not have a postmortem examination. Of the twenty patients with dislocated prostheses, eleven required further operation and nine of these subsequently became infected, two being deep infections.

The surgical approach had a marked influence on the dislocation rate. Only one dislocation occurred in the 107 patients following the anterior approach, compared with nineteen dislocations in the 136 patients whose operations were by the posterior approach (Table VIII). Radiological assessment of anteversion and retroversion is difficult after a Thompson replacement because of the short neck. Despite this, radiographic review in the dislocated group revealed seven cases of retroversion varying from 8 to 22 degrees, only three of which were in excess of 20 degrees. The antero-posterior radiograph 
showed inadequate removal of the femoral neck in five cases.

A further factor of significance concerns the use of bone cement to secure the prosthesis in the medullary canal of the femur. Fifty-three prostheses were inserted without using cement (twenty-eight cases in the anterior group; twenty-five in the posterior group). None of the uncemented prostheses dislocated after the anterior pin track through the femoral cortex. Only one cortical penetration, however, required revision; the remainder caused no symptoms. There were three instances of sciatic nerve injury, all in the posterior group. Two of these were secondary to dislocations. One patient developed myositis ossificans approximately six weeks after replacement through the anterior route.

Discharge rate-The rate of discharge from hospital at

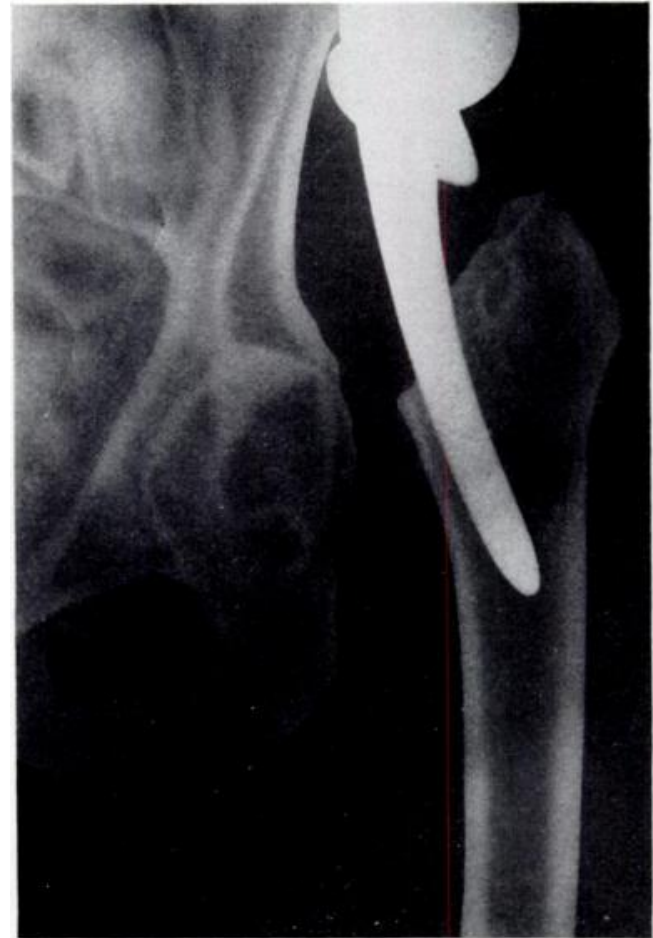

Fig. 1

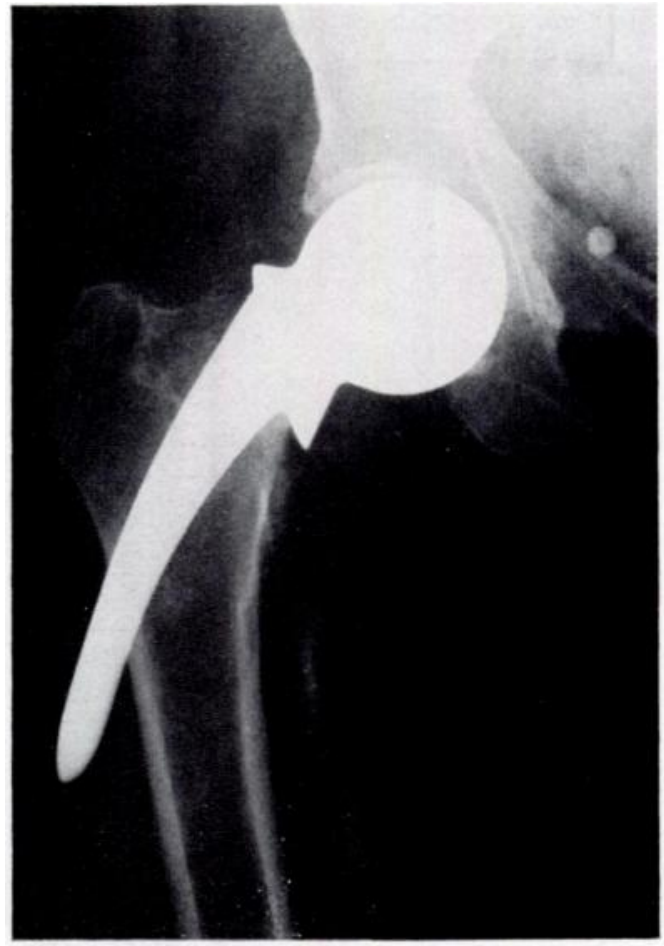

FIG. 2

Figure 1-A radiograph showing dislocation of a Thompson prosthesis from the acetabulum, with displacement and rotation of the stem within the femoral shaft. The prosthesis had been inserted through a posterior approach and bone cement had not been used. Figure 2-A radiograph showing penetration of the lateral femoral cortex by the stem of a Thompson prosthesis.

approach, but eight of the twenty-five uncemented prostheses dislocated when the posterior route was employed. The management of this complication is particularly difficult: not only does the head dislocate from the acetabulum, but the prosthesis tends to rotate within the femoral shaft (Fig. 1). This makes closed manipulation frequently impossible, and six of these eight dislocations required further operation.

Although the clinical state of the patient, correct siting and fixation of the prosthesis may all influence the subsequent dislocation rate, in this series the most important single factor was the choice of surgical approach, and our results indicate the comparative instability created by the posterior approach.

Other complications-Fracture of the greater trochanter occurred twice and penetration of the lateral femoral cortex by the prosthetic stem four times (Fig. 2). These complications all occurred in the anterior approach group. Three of these cases were secondary prostheses for failed pins, and the stem of the prosthesis followed the the sixth post-operative week was assessed. By discharge we include return home or to the institutions whence they came, and transfer to smaller peripheral hospitals for convalescence. Patients in the latter group required no special orthopaedic care and transfer was for general nursing care and most frequently for social reasons. The discharge rate is therefore an indicator of post-operative morbidity and comparison of the two groups is of interest (Table IX). The discharge rate of 79 per cent at six weeks in the anterior group reflects a lower morbidity compared with the discharge rate of 61 per cent in the posterior group $(\mathrm{p}<0.01)$.

Mortality rate-The overall mortality rate of 14.4 per cent at six weeks is in general agreement with other reports from Britain (Burwell 1967; Hunter 1969; Wrighton and Woodyard 1971). When analysed in terms of the two groups, a marked difference is apparentagain in favour of the anterior approach. The mortality rate for this latter group was low (6.5 per cent) compared with 20.6 per cent seen in the posterior group (Table IX). 
Even discounting the increased number of dislocations via the posterior approach, the resulting mortality rate of 16 per cent for this group remains very high. Since the patients in both groups were in all other: respects similar, it is apparent that the choice of surgical approach to the hip influences both the morbidity and mortality to a great extent $(p<0.01)$.

TABLE IX

Mortality and Discharge Rates Six Weeks after Operation

\begin{tabular}{|c|c|c|c|}
\hline & & $\begin{array}{l}\text { Discharge rate } \\
\text { (per cent) }\end{array}$ & $\begin{array}{l}\text { Mortality rate } \\
\text { (per cent) }\end{array}$ \\
\hline Anterior group & . & 79 & $6 \cdot 5$ \\
\hline Posterior group & . $\quad$. & 61 & $20 \cdot 6$ \\
\hline
\end{tabular}

Autopsy information, available in thirty-two out of thirty-five patients, recorded the causes of death as pneumonia twelve; pulmonary embolism ten; cerebrovascular accidents five; myocardial infarction four; operative deaths two.

Of the operative deaths, one was considered to result from the insertion of cement (no other cause of death being apparent at necropsy) and the other resulted from pulmonary embolism. While the importance of deep vein thrombosis and its fatal sequelae is appreciated, no attempt has been made to analyse this complication because clinical findings are now known to have only marginal relevance to the clinical situation as a whole.

\section{DISCUSSION}

Fracture of the femoral neck is the commonest cause of death from violence over the age of seventy-five (RegistrarGeneral 1971) and its incidence continues to increase. The number of patients with femoral neck fracture admitted to hospital in this country was 17,000 in 1960 , 26,810 in 1969 and 29,340 in 1970 (Keith 1973). There can therefore be no dispute about the importance of this fracture, not only as a clinical problem but also as an increasing burden in terms of cost and total patient care.

It is beyond the scope of this report to enter into the "pin versus prosthesis" controversy. However, we share the concern of some recent authors with regard to the results of prosthetic replacement, especially in relation to infection, dislocation and mortality (Hunter 1969, 1974; Lunt 1971; Raine 1973). Nevertheless, prosthetic replacement remains a valuable operation, and even the most ardent supporters of internal fixation find recourse to the prosthesis in the management of irreducible fractures or for late complications of pinning. Analysis of complications arising from this operation is therefore of value, especially if accompanied by guidance as to how they can be avoided.

Comparison of results published in different series becomes meaningless when several variable factors are present. Moore's personal series (1957) contained, for example, twelve patients aged less than thirty, and this factor alone would have a significant effect on mortality and norbidity. Some authors have included a variety of prostheses in their reports (Anderson et al. 1964; Burwell 1967; Lunt 1971). Several papers present composite results of prosthetic surgery for a diversity of hip disorders-fractures, osteoarthritis, rheumatoid arthritis and avascular necrosis (Barr, Donovan and Florence 1964; Anderson et al. 1964)-and Moore's series (1957) included sixteen different diagnoses. By confining this report to a group of patients with subcapital fractures treated at one centre with the same type of prosthesis, it became possible to compare the only remaining variable, namely, the surgical approach to the hip. The summarised comparison of results (Table $\mathrm{X}$ ) shows clearly a reduction in morbidity and mortality when the anterior route was employed.

TABLE X

Summarised Comparison of Results and Complications

\begin{tabular}{|c|c|c|c|}
\hline & & $\begin{array}{l}\text { Anterior } \\
\text { approach }\end{array}$ & $\begin{array}{l}\text { Posterior } \\
\text { approach }\end{array}$ \\
\hline Average blood loss & . & 440 millilitres & 600 millilitres \\
\hline Penetration of lateral cortex & . & 4 & $\mathbf{0}$ \\
\hline Fracture greater trochanter & . & 2 & 0 \\
\hline Myositis ossificans & . & 1 & 0 \\
\hline Foot drop & 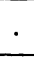 & 0 & 3 \\
\hline Dislocation rate & . & 0.9 per cent & 14 per cent \\
\hline Infection rate & . & 6.5 per cent & 18.5 per cent \\
\hline Further operation required & . & 3 & 11 \\
\hline Discharge rate at six weeks & ${ }^{\circ}$ & 79 per cent & 61 per cent \\
\hline Death rate at six weeks. & ${ }^{\circ}$ & 6.5 per cent & 20.6 per cent \\
\hline
\end{tabular}

Comparison of the dislocation rates $(0.9$ per cent anterior; 14 per cent posterior) suggests an inherent instability in the posterior approach when the Thompson prosthesis is used. The design of the Thompson prosthesis with its curved varus stem facilitates insertion through an anterior incision, and Thompson himself preferred the Smith-Petersen approach (Thompson 1954). Insertion of this prosthesis by the "southern approach" may well prejudice the result. The point is further emphasised by the fact that eight of twenty-five uncemented prostheses inserted posteriorly subsequently dislocated, compared with none of twenty-eight uncemented prostheses in the anterior group.

An important benefit of the anterior route is that it permits early adoption of the safe sitting position, whether in or out of bed. Similarly, the integrity of the posterior capsule makes the anterior approach much safer in patients with spasticity from cerebro-vascular accidents, 
for the not infrequent combination of flexion and adduction contractures in these patients makes the posterior route hazardous. After the posterior approach, the prosthesis is most stable with the hip in extension and lateral rotation; thus the post-operative regime for many patients in this group often requires them to be nursed supine in operative events. In the posterior group eleven dislocations occurred in forty-eight hips recorded as being stable, whereas of eleven hips noted to be unstable at the time of operation only two dislocated.

Traction was used after operation in $\mathbf{4 5}$ per cent of cases in the posterior group: it consisted of skin traction of

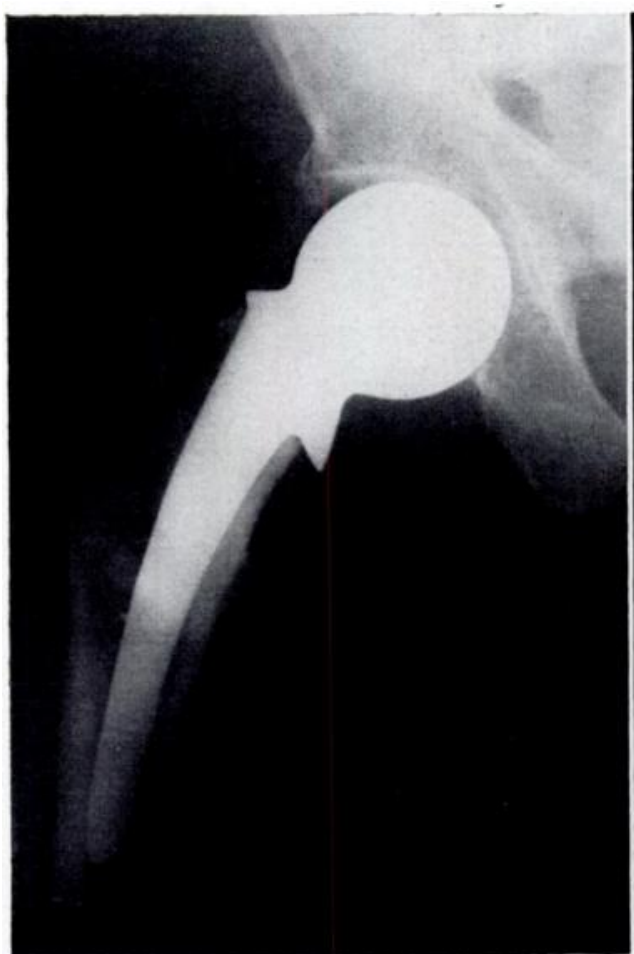

Fig. 3

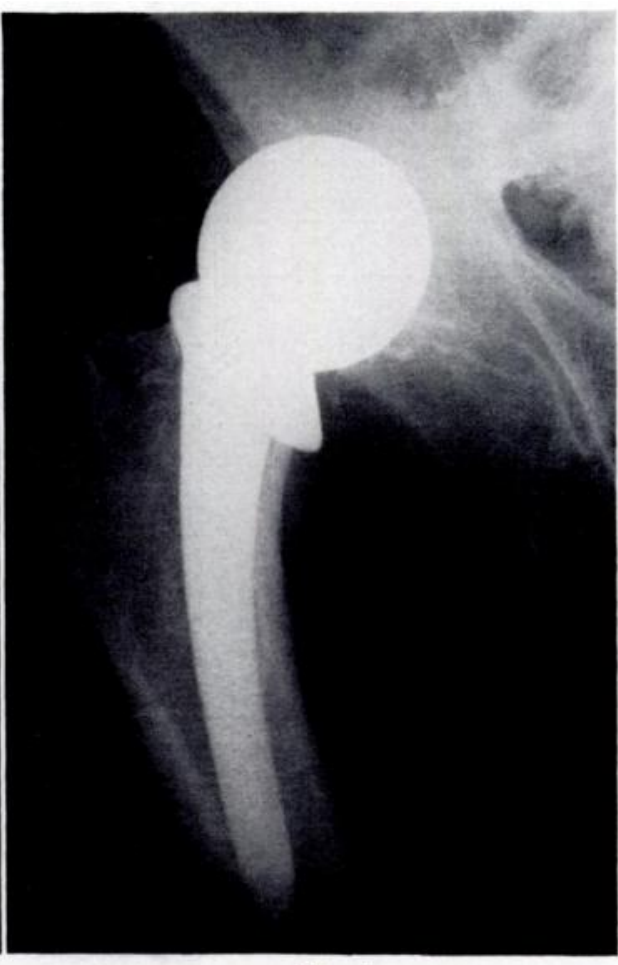

Fig. 4

Figure 3-Inadequate resection of the femoral neck, as shown in this radiograph, endangers the stability of the prosthesis. Figure 4-A radiograph taken twelve days after operation showing dislocation of the prosthesis.

bed for several days. Such a regime negates the concept of early mobilisation and encourages chest infections and pressure sores. Moreover, we question the value of the supine position in preventing dislocation. Seventy-five per cent of dislocations in the posterior group occurred during the first two weeks, often while the patient was still confined to bed. Observation of the standard nursing procedure in turning patients shows the difficulty

TABLE. XI

Correlation of Dislocation and Post-operative Traction (Posterior group)

\begin{tabular}{|cccccc|}
\hline & & & Traction & No traction \\
\hline Dislocation & $\cdot$ & $\cdot$ & $\cdot$ & $\cdot$ & 10 \\
\hline No dislocation. & $\cdot$ & $\cdot$ & $\cdot$ & 51 & 9 \\
\hline
\end{tabular}

of maintaining these hips in the "stable" position of extension and lateral rotation.

The seeming stability of the prosthesis following reduction at operation was no accurate guide to post-
2 to 3 kilograms, without a derotation device, maintained over an average period of seven to ten days. The value of this regime is questionable because dislocation occurred with equal frequency with or without traction (Table XI).

Although incorrect version of the prosthesis is frequently emphasised as a major cause of dislocation, we noted only three instances of retroversion in excess of 20 degrees. However, even minor degrees of malpositioning in combination with excessive residual neck length, as noted in five patients, will prejudice stability to the point of dislocation (Figs. 3 and 4).

Infection is a major worry with all prosthetic surgery. In our series similar numbers in each group developed staphylococcus aureus infections. This is hardly surprising because both groups were exposed to the same hospital environment and therefore were equally susceptible to air-borne organisms. However, the higher incidence and the type of organisms in the posterior group indicate a high level of autogenous infection. It seems logical that incisions sited in a potentially contaminated area (buttock) in the elderly carry a high risk of infection and our observations support this. While we are satisfied 
that antibiotic regimes did not give bias to either group, we are not in a position to discuss their efficiency for reasons outlined previously. Nevertheless, prophylactic antibiotics may well have a place in redueing infection after the posterior exposure especially in the presence of urinary or faecal incontinence.

The advisability of routine suction drainage was questioned by Wrighton and Woodyard (1971), who demonstrated an increased infection rate in their drained wounds. While admitting that their numbers were small and of doubtful significance, they suggested that further investigation was necessary. Our results are statistically highly significant $(p<0.001)$ and therefore indicate that routine suction drainage is advisable in all cases (Table VI).

The mentally retarded, the incontinent and those subjected to secondary prosthetic replacement after unsuccessful pinning are "high risk" groups which are particularly liable to complications and merit careful attention at all stages. We would agree with the late John C. Wilson, as quoted by Boyd and Salvatore (1964): "This is a dangerous operation-it is too easy to do." If the Thompson prosthesis is to remain part of our surgical repertoire we advise its insertion through an anterior approach.

We wish to thank the consultant orthopaedic staff of the Bath and Wessex Orthopaedic Hospital, Bath, for permission to study patients under their care; we are indebted to the Department of Medical Illustration, Oxford, and to Mrs Christine Whittle, secretary.

\section{REFERENCES}

Anderson, L. D., Hamsa, W. R., Jun., and Waring, T. L. (1964) Femoral-head prostheses. Journal of Bone and Joint Surgery, 46-A, $1049-1965$. Badgely, C. (1961) Treatment of displaced subcapital fractures of the femoral neck in the aged by immediate replacement arthroplasty (discussion). Journal of Bone and Joint Surgery, 43-B, 606.

Barr, J. S., Donovan, J. F., and Florence, D. W. (1964) Arthroplasty of the hip. Journal of Bone and Joint Surgery, 46-A, $249-266$.

Boyd, H. B., and Salvatore, J. E. (1964) Acute fracture of the femoral neck: internal fixation or prosthesis? Journal of Bone and Joint Surgery, 46-A, 1066-1068.

Burwell, H. N. (1967) Replacement of the femoral head by a prosthesis in subcapital fractures. British Journal of Surgery, 54, 741-749.

Henry A. K. (1957) Extensile Exposure. Second edition, pp. 210-212. Edinburgh and London: E. \& S. Livingstone Ltd.

Hinchey, J. J., and Day, P. L. (1964) Primary prosthetic replacement in fresh femoral-neck fractures. Journal of Bone and Joint Surgery, 46-A, 223-240.

Hunter, G. A. (1969) A comparison of the use of internal fixation and prosthetic replacement for fresh fractures of the neck of the femur. British Journal of Surgery, 56, 229-232.

Hunter, G. A. (1974) A further comparison of the use of internal fixation and prosthetic replacement for fresh fractures of the neck of the femur. British Journal of Surgery, 61, 382-384.

Keith, S. (1973) The Hospital In-patient Enquiry 1970. Health Trends, 5, 13-14.

King, D. (1964) Primary prosthetic replacement in fresh femoral-neck fractures (discussion). Journal of Bone and Joint Surgery, 46-A, 240.

Lunt, H. R. W. (1971) The role of prosthetic replacement of the head of the femur as primary treatment for subcapital fractures. Injury, $3,107-113$.

Moore, Austin T. (1957) The self-locking metal hip prosthesis. Journal of Bone and Joint Surgery, 39-A, 811-827.

Moore, Austin T. (1959) The Moore self-locking Vitallium prosthesis in fresh femoral neck fractures. A new low posterior approach (the southern exposure). American Academy of Orthopaedic Surgeons Instructional Course Lectures, 16, 309-321.

Nicoll, E. A. (1963) The unsolved fracture. Journal of Bone and Joint Surgery, 45-B, 239-241.

Polyzoides, A. J. (1971) Prosthetic replacement after femoral neck fractures (short and long-term follow-up). Injury, 2, $283-286$.

Raine, G. E. T. (1973) A comparison of internal fixation and prosthetic replacement for recent displaced subcapital fractures of the neck of the femur. Injury, 5, 25-30.

Registrar-General (1971) Abridged Life Table 1968-1970 (home population) England and Wales. Registrar-General's Quarterly Returns England and Wales. Quarter ended 30 June 1971. No. 490, p. 35. London: H.M.S.O. Office of Population Censuses and Surveys.

Riska, E. B. (1971) Prosthetic replacement in the treatment of subcapital fractures of the femur. Acta orthopaedica Scandinavica, 42, 281-290.

Thompson, F. R. (1954) Two and a half years' experience with a Vitallium intramedullary hip prosthesis. Journal of Bone and Joint Surgery, 36-A, 489-500.

Wrighton, J. D., and Woodyard, J. E. (1971) Prosthetic replacement for subcapital fractures of the femur: A comparative survey. Injury, 2, 287-293. 